\title{
Index of Names
}

Albert, David 368-9

Alston, William 156

Altidore, Jozy 234

Appiah, Kwame

Anthony 151-2

Aristotle 2, 14,

101n.44, 109,

122-6, 129-130,

133, 135, 137, 179,

318-19, 333-364

Armstrong, David 2,

119n.17, 121n.21,

156-7, 159, 251-5, 257, 295

Arnold, Matthew 151

Audi, Paul 9n.36,

24n.3, 26n.12

Ayer, A.J. 115n.8,

117n.11, 283

Azzouni, Jody 302,

304n.30

Bagpuss 257

Balkin, J.M. 238n.18, 241, 242n.31

Baumberger,

Christoph 8

Baxter, Donald 251-

3, 255n.19, 353n.32

Beebee, Helen 283-5

Beisbart, Claus 8

Bell, John 371, 390

Benacerraf, Paul 85, 114n.7

Bennett, Karen 3n.12, 22n.64, 47n.7,

60n.23, 249n.2,

334-7

Berkeley, George 369
Bernoulli, Daniel 9

Berto, Francesco 301

Blackburn, Simon

115-16, 127-8

Bohr, Niels 369-71, 373, 376

Bradley, F.H. 255

Brandom, Robert 155, 239n.24, 324

Brogaard, Berit 165-187, 312n.3, 318 n. 20

Brun, George 8

Burge, Tyler 103

Burgess, Alexis

147n.21, 153

Burgess, John P. 249

Buonarrotti,

Michaelangelo 317

Cantor, Georg 87, 97, 106

Carmichael, Chad 47n. 4,70

Carnap, Rudolf 141, 143, 145, 194, 216n.32, 218n.41, 219n.45, 298n.16

Carroll, John 22

Chalmers, David 3n.11, 23n.1, 96n. 37

Chip (example) 213-17

Coliva, Annalisa 224

Correia, Fabrice 3n.11, 19n.58, 24n.6, 96n.35, 312 n. 3, 330, 361 n. 40
Coyote, Wile E 366-7, $368,374,377,385$, 393

Daly, Chris 26-7

Dasgupta, Shamik, 17, 22n.64, 29n.19

Davies, David 144, 151

de Broglie, Louis 371

Dedekind, Richard 79, 88n.26

Della Rocca, Michael 312 n. 3, 313, 315

Denby, David 312n.3, 317

Dorr, Cian 45n.1, 47n.4, 54n.16, 69

Dummett, Michael 87-90, 97, 105, 114-16, 118

Eiffel, Gustave 148, 311, 316

Einstein, Albert 369-71, 374, 388n.55, 390

Eklund, Matti 47n.7, 294n.5, 298n.17, 301,307 n.33

Elmo (muppet) 82, 85-87

Euclid 13, 98, 101, 103-4

Evans, Gareth 209, 213n.27, 216n.33, 217 n.34

Evans-Pritchard, Edward 306 
Field, Hartry 39, 41, 141n.6, 161, $295 n .7$

Fine, Kit 3, 17, 19, 24n.3, 29, 33, 34, 40, 41n.46, 42, 47n.7, 96, 123-4, 126, 196, 203, 247n.45, 311-12, 314, 317, 318n.21, $319,332,333$, 334n.4, 335n.7, 338n.13, 344n.19, 351n.29, 358n.37, 361-2

Fraenkel, Eduard 13, 81n.8, 106

Frege, Gottlob 47n.7, 77-107, 110n.1, 125n.26, 134, 141n.7, 294n.5

Gaifman, Haim 372, 374-6

Gert, Bernard 144

Gert, Joshua 144

Gibbard, Allan 43, $333-4,342-3,345-$ $6,348,350$

Gibson, James 194

Gilder, Louise 370

Glazier, Martin 2, 16, 19,22 n. 64

God(s) 2, 18, 311, 378, 383, 391

Gödel, Kurt 365, 3714, 376-7, 388n.55

Goliath 332-3, 342-8, $350,355-8$

Grimm, Stephen 8, 9n.33

Grover (muppet) 87
Hale, Bob 3n.9, 82, 85-8, 109-138, 141n.7, 295n.7, 318n.21, 358n.37, 362n. 41

Haslanger, Sally 144, 152, 231-247

Hawthorne, John 4575,262 n. 33

Haydn, Joseph 109

Hazen, A.P. 249

Hazlett, Alan 325, 326n. 37

Heidegger, Martin 385-7

Heisenberg, Wener 371

Hesperus 112

Hilbert, David 372-4, 376

Hirsch, Eli 46n.3, 149n.22, 289n.1, 290, 293, 294n.5, 301

Hofweber, Thomas 4, 9, 26n.9, 27, 95n.33

Hoffmann, Aviv 3, 112n.2, 116n. 8

Holland, Nancy 3827, 389

Hume, David 22, 79 , 106, 121, 193-4, 219, 381

James, William 255

Jefferson, Thomas 151 Jeshion, Robin 101-2, 104

Jocasta 314-16

Kane, Robert 268n.7, 273n.12, 278n.23, 285
Kim, Jaegwon 5, 8, 12, 30n.23, 33, 101n.44, 159n.47, 196n.9

Kment, Boris 2, 6, 16, 17, 19

Korman, Daniel 45-75

Kripke, Saul 112, 117, 123, 189, 192, 1956, 200, 234n.6, 321n.30, 329n.35

Kukla, Rebecca 234n.5, 243, 244

Lance, Mark 234n.5, 243, 244

Langton, Rae 317

Leibniz, Gottfried 99, 136, 334, 350-1, 366

Lewis, C.S. 325

Lewis, David 2, 5, 27, $37,53,111,114$ n.5, 118-121, 140, 157, 194-5, 200, 249-63, 295n. 9, 317, 325, 331, 353n.32, 359n. 37,378

Linnebo, Øystein 802, 88-90, 92, 93, 95

Locke, John 144, 145n. 15, 151, 334n.4

Ludlow, Peter 146

Lumpl 332-3, 342-8, $350,355-8$

MacBride, Fraser 1, 324n.35

Mackie, J.L. 32-33

Mackie, Penelope 117n.12, 265-287, 325n.36, 326, 359n.37 
Manley, David 3n.11, 23n.1, 96n.37

Marmodoro, Anna 338n.13, 343n.19, 346-7

Maudlin, Tim 22

McKenna, Michael 265n.1, 267n.4, 268n.7, 269

Mele, Alfred 267n.4, 269n.9, 273n.12, 279, 280n.24, 287n. 35

Millikan, Ruth 144

Mog 257

Mozart, Wolfgang Amadeus 109

Murdoch, Iris 386, 387, 391-3

Neurath, Otto 381, 389

Nicomachus 135

Nietzsche, Friedrich 199, 202

Nozick, Robert 8

Oedipus 314-16

Orla 258

Orlando 258

Otis 258

Parsons, Terence 302

Pasternak, Boris 1

Pauli, Wolfgang 371

Peano, Giuseppe 79, 373, 375

Pereboom, Derk 268n.7, 269

Phaenarete 310, 317

Phaestis 135

Phosphorus 112

Plantinga, Alvin 129, 359n.37
Plato 2, 13, 310, 313, $326,338 n .13$

Plebani, Matteo 301

Putnam, Hilary 7 , 140n.5, 226n.64, 227n.64, 290

Quine, W.V.O. 2, 118, 155-6, 194-5, 203, 302, 304

Rawls, John 233-5

Read, Stephen 378

Resnik, Michael 81

Rosen, Gideon 1-2, 9n.36, 16, 17, 20n.62, 23n.2, 26n.11, 27, 29n.19, 35-6, 47n.4, 295n.9, 319

Rosenkrantz, Gary 70n.44, 71n.44

Rouse, Joseph 234n.6, 240

Rowling, J.K. 325

Ruben, David-Hillel $5,12 \mathrm{n} .43$

Russell, Bertrand 845, 88, 102, 105, 296-7

Ryle, Gilbert 155

Sainsbury, Mark 229n.70, 302

Salmon, Wesley 5 Schaffer, Jonathan 122, 23n.1, 24n.3, 96, 249n.2, 256n.23, 262n. 32

Schnieder, Benjamin 3n.11, 19n.58, 24n.7, 96n.35, 361 n. 40

Scriven, Michael 5, 11

Searle, John 156

Sewell, William 238, 239n.25, 241n.29, 243, 246

Shapiro, Stewart 77108

Shelby, Tommie 231

Sidelle, Alan 117n.12, 336n.10, 339-42, 348 n. 26

Sider, Ted 22n.64, 24n.4, 60n.23, 67n.36, 96, 140n.3, 141, 157, 158n.43, 196, 197n.11, 336n.9

Skiles, Alex 22n.64, 316, 317n.16

Skow, Bradford 5, 11

Skyrms, Brian 7-8

Smaug (dragon) 37

Smith, Barry 165-187

Socrates 2-4, 13-15, $18,20,32,62-3$, 196, 310-11, 31314, 316-17, 319, 321-3, 325-6, 328, 331, 354, 356, 360-1

Stalnaker, Robert 112n.2, 114n.5, 195, 239n.23

Steiner, Mark 367, 370, 371

Stillwell, John 374n.24, 375, 377

Strevens, Michael 5, 8

Tennant, Neil 82

Tumnus (Mr) (faun) 325 


\section{Index of Names}

van Inwagen, Peter 60n.23, 61-2,

141n.6, 252n.12, $253,260,267,276-8$

von Neumann, John

74, 81n.8, 97, 106

Wainer, Stanley 375

Wallace, David 32

Walton, Kendall 38

Wang, Hao 372,

$373 n .22$

Wasserman, Ryan

3n.11, 23n.1, 96n.37

Whitehead, A.N. 105, 118 n.13

Wiggins, David 181, 316n.15, 324n.34, 326n.40, 327, $328 \mathrm{n} .42$

Williamson, Timothy 112n.2, 129, 130n.30, 189-204, 239n.24, 261n.31, $315 n .12$

Wilsch, Tobias 2, 9 n. 36, 16, 22n. 64

Wilson, Jessica 4, 14n.47, 22n.64, 26n. $9,28-9$, 40n.43, 44n.51 Wilson, Mark 368, 372, 380-2, 384, 389-93

Wittgenstein, Ludwig 112, 114n.6, 118n.14, 205-229, 234n.6, 338n.13

Woodin, Henry 376, 377

Woodward, James 5, 6 n. $23,7,9$ n. 33 , 12 n. 43

Wright, Crispin 79, 82, 85n.23, 95n.33, 115 n. 8,141 n.7, 214n.29

Yablo, Stephen 47n.7, 60n.23, 117n.12, 154, 155n.32, 160, $337 \mathrm{n} .11$

Zach, Richard 372

Zermelo, Ernst 13, 81n.8, 106 


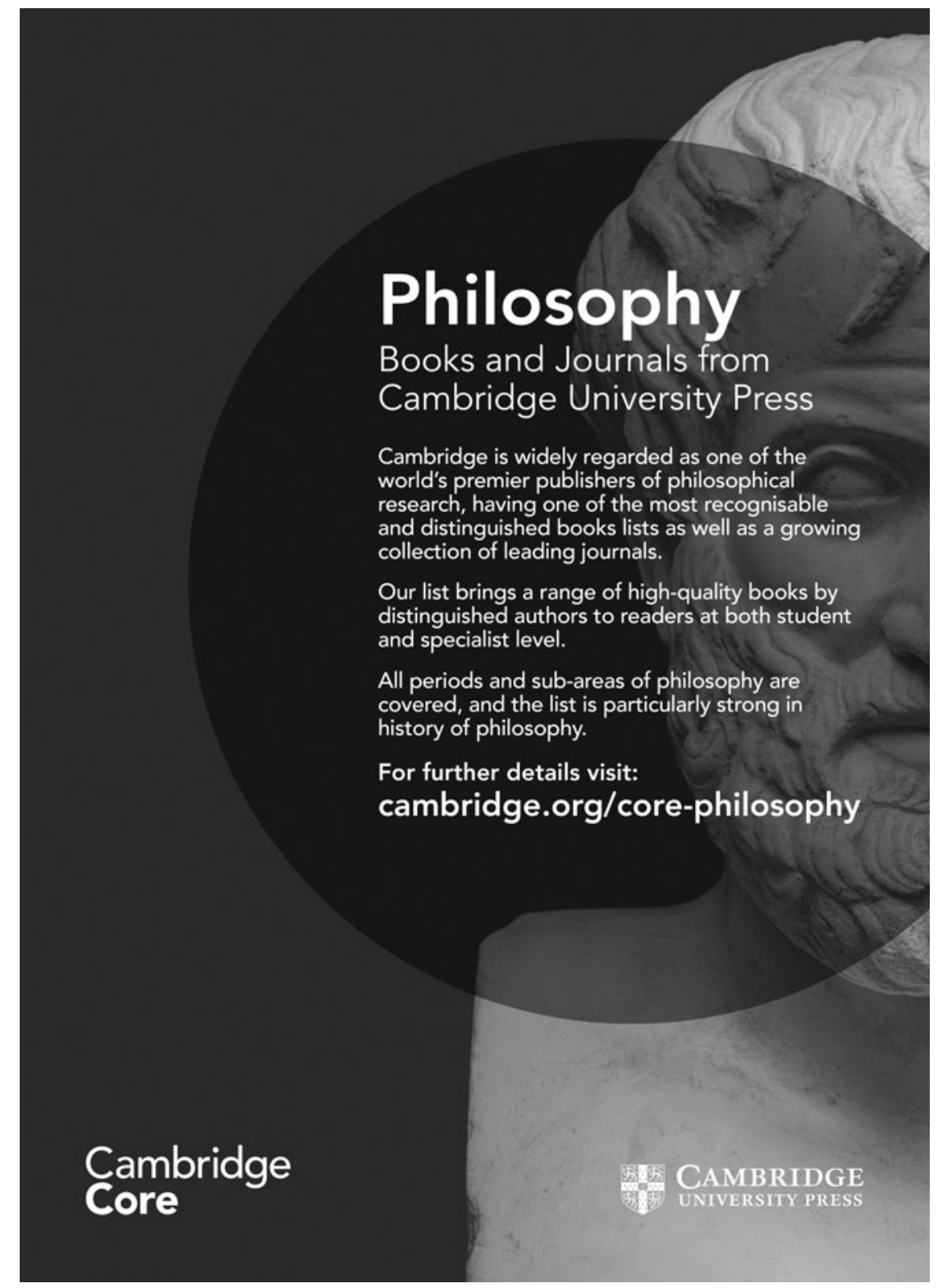




\section{Metaphysics}

This volume is based on the lectures given in London as The Royal Institute of Philosophy's annual lecture series for 2016-7. The topic chosen for the series was Metaphysics, an area where at the moment there is much exciting and innovative work being done. As will be clear from the list of authors, many of the leading figures in contemporary metaphysics are represented here. The volume thus testifies to the fruitfulness of the subject, as well as making a significant contribution to its development.

Several papers in the volume consider the nature of metaphysical explanation, its scope and limits. The currently fashionable notion of grounding is taken up by a number of our authors, while there are also papers arguing for optimism about the potential scope of metaphysical explanation and against conservative restrictions on what should be countenanced in metaphysics. The prospects for a Fregean account of number are considered, as well as the question of quantifier variance.

As would be expected, there are papers on such central metaphysical topics as essence, necessity, possibility and identity. Ranging wider, and testifying to the breadth of metaphysics as a subject, there are treatments of free will, of solipsism in Wittgenstein's philosophy of the 1930s, of the nature of social practices, of the notion that the conceptual recommendations of metaphysics are to do with assessing and perhaps changing the way we live, and also a consideration of the ontological status of the foetus and the unborn child.

\section{Contributors}

Jonathan Schaffer, Naomi Thompson, Maegan Fairchild, John Hawthorne, Eric Snyder, Stewart Shapiro, Richard Samuels, Bob Hale, Amie Thomasson, Elselijn Kingma, Timothy Williamson, Tim Button, Sally Haslanger, Katherine Hawley, Penelope Mackie, Suki Finn, Otávio Bueno, Jessica Leech, Kathrin Koslicki and Penelope Rush.

\section{Cambridge Core}

For further information about this journal

please go to the journal website at:

cambridge.org/phs

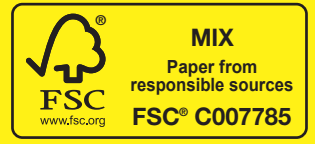

CAMBRIDGE UNIVERSITY PRESS

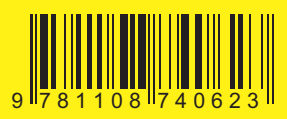

